\title{
Caregivers' burden and needed support for the care of dementia patients attending Ain Shams University hospitals
}

Nourhan Samy Ata ${ }^{1}$,Marwa Abdel Azeem Abdel Gawad ${ }^{1}$, Heba Youssif Youssif ${ }^{1}$, Sally Adel Hakim ${ }^{1}$, Shereen Moustafa Mousa ${ }^{1}$

${ }^{1}$ Geriatrics and Gerontology Department, Faculty of Medicine Ain Shams University.

${ }^{3}$ Department of Community, Environment and Occupational Medicine, Faculty of Medicine Ain Shams University

\begin{abstract}
Background: Dementia in late stages affects patients' life like being dependent, malnourished, having psychological and sleep problems. Caregivers face physical, financial, medical, and psychological burdens and are in need for support to complete caregiving responsibilities. Not all caregivers have the sufficient knowledge regarding how dementia affects the patients.
\end{abstract}

Aim: To determine the burden of caregiving process on caregivers of moderate to severe and severe dementia patients, the type of support and knowledge that caregivers need during this process

Methods: a cross-sectional study involving 101 caregivers of moderate to severe and severe dementia patients attending outpatient clinics and inpatients in Ain Shams University Hospitals. Demographic data of the patients and their caregivers were collected. A questionnaire was applied on caregivers including types of burden they experienced, types of support they needed and their knowledge about dementia \& its effect on patients' life.

Results: Most caregivers had different types of caregiving burdens. Ninety-eight percent ( $98 \%)$ of them had fear of future burden, $89 \%$ had physical\& psychological burden and $69 \%$ had financial burden. Most caregivers needed support in caregiving. Eighty percent $(80 \%)$ of them needed medical support, $59.4 \%$ needed physical support, $54.5 \%$ needed psychological support, $47.5 \%$ needed financial support, while only $8.9 \%$ needed social support. None of the caregivers had accurate previous knowledge about dementia. Ninety-three percent (93\%) of caregivers predicted that dementia patients might need special care. Regarding dementia effect on patients, $88.1 \%$ of caregivers knew it had an effect on patients' behavior, $74.3 \%$ knew it affects sleep, $54.5 \%$ knew it affects safety, $53.5 \%$ agreed with its effect on patients' activity and $48.5 \%$ knew it affects nutrition

Conclusion: Caregiving of moderate to severe and severe dementia patients is associated with huge physical, psychological and financial burdens. Most of the caregivers are in need of more support and knowledge to help them alleviate their burden and improve patients' care and quality of life.

Keywords: dementia, caregivers, burden, support, knowledge.

\section{Background}

The Diagnostic and statistical manual of mental disorders-5 (DSM-5) characterizes dementia as a substantial impairment in one or more cognitive domains (memory, communication, language, attention, reasoning, and visual perception). This impairment must be sufficient to interfere with independence in everyday activities, not exclusively during delirium or explained by another mental disorder. (Edition F.
DSM-5, 2013)

In Egypt, the prevalence of dementia among individuals aged $\geq 50$ years was estimated to be $2.01 \%-5.07 \%$. (Elshahidi et al., 2017). In USA, the number of aged 65 and older with Alzheimer's dementia (AD) by mid-century may grow to 13.8 million. This represents a steep increase from the estimated 5.7 million Americans who have Alzheimer's dementia today. 
(Alzheimer's Association, 2018)

Early on, the goal of dementia care is to preserve functional status. However, as the disease progresses, goals shift to maintaining the ability to live at home, maintaining mobility, reducing caregiver burden and controlling behavioral \& psychological problems. (Case et al., 2015)

Alzheimer's Association, (2012) found that more than $80 \%$ of $\mathrm{AD}$ caregivers frequently reported high levels of stress and half reported suffering from depression and anxiety. Eighty-one $\%$ of caregivers of dementia patients complained of at least one illness and $60.5 \%$ complained of multiple illnesses. Compared to noncaregivers, caregivers had a higher prevalence of chronic illnesses, such as depression, hypertension, arthritis, and heart disease (Wang et al., 2014)

According to Alzheimer's Association, the total direct medical expenditures associated with dementia types in the United States will increase from $\$ 236$ billion in 2016 to more than $\$ 1$ trillion in 2050 due to projected increase in the elderly population. (Alzheimer's Association, 2016)

Caregivers of people with dementia may be less able to cope with stressors as they have high rates of financial, emotional and physical difficulties associated with caregiving. (Freedman \& Spillman, 2014). Therefore, Caregivers of dementia patients have difficulty in maintaining social relationships with family and friends. They feel isolated and alone, lack familial and community supports, and express a need for social support. (Grigorovich et al., 2016)

Therefore we need to know the burden of dementia caregiving in moderate to severe and severe stages on Egyptian caregivers, which kind of support they are in need and their knowledge about the disease and its effect of the patients.

\section{Methods}

The present study is a cross-sectional study that included 101 caregivers of moderate to severe and severe dementia patients according to Global Deterioration Scale (GDS) (Reisberg et al., 1982). They were interviewed at outpatient clinics and inpatients of Ain Shams University Hospitals after taking informed consent from them.

For patients: Comprehensive geriatric assessment was done including (detailed history: demographic data, medical history, drug history, dementia history and problems related to it, and application of Mini Mental State Examination (MMSE) (Folstein et al., 1975), Activities of Daily Living (ADL) (Katz et al., 1963) and Instrumental Activities of Daily Living (IADL) (Lawton et al., 1969).

For caregivers: the following data were collected through a questionnaire that was applied on caregivers which included, the presence of any burden (physical, financial and psychological), type of support needed (medical, physical, psychological, financial and social) and their knowledge about dementia \&its effect on sleep, nutrition, behavior and activity.

(demographic data, caregiving time/day, relation to the patient, previous training, type of burden felt by the caregiver, and care and support needed for proper care) 2.1. Statistical Analyses

Analysis of data was performed by using the $23 \mathrm{rd}$ version of Statistical Package of Social Science (SPSS). Description of all data in the form of mean (M) and standard deviation (SD) for all quantitative variables. Frequency and percentage for all qualitative variables. Comparison of qualitative variables was done using Chi-square test or Fisher Exact.

Comparison of quantitative variables between different groups using Student t-test or One way ANOVA test. Significance level was determined according to $\mathrm{P}$-value (Probability): $\mathrm{P} \geq 0.05$ is insignificant, $\mathrm{P}<0.05$ is significant and $\mathrm{P}<0.01$ is highly significant.

Ethical considerations

The study was performed in adherence to the principles established by the Declaration of Helsinki and the study methodology was reviewed and approved by Ethical Committee of Scientific research and the Research Review Board of the Geriatrics and Gerontology Department, Faculty of Medicine, Ain Shams University. Informed verbal consent was obtained from all the participants because some of the participants were illiterate and could not provide signed consent. The ethics committee approved using verbal consent.

\section{Results}

The current study is a cross-sectional study. The study population was 101 caregivers of moderate to severe and severe dementia patients. Comprehensive geriatric assessment was applied on all selected patients.

The mean age of the study participants was $73.7 \pm$ 6.44 years. All of them reported living at their homes mostly receiving caregiving services $(98 \%)$ from at least one caregiver $(57.4 \%)$. Most of them were females $(71.3 \%)$, widow/widower $(67.3 \%)$, illiterate $(53.5 \%)$ and reported having a sufficient income (52.5\%). (Table.1)

Most of the patients had severe dementia (GDS=7, $60.4 \%$ ) with a mean MMSE of $15.6 \pm 3.53$, totally dependent in IADL (59.4\%) and ADL (47.5\%). (Table 2)

Socio-demographic data from all caregivers were obtained. Their mean age was 46.4 years, $81.2 \%$ were first-degree relatives to the patients, $70.3 \%$ were females, $62.4 \%$ got post-secondary education, $57.4 \%$ provide both physical and financial support, $52.5 \%$ of patients have multiple caregivers, $53.5 \%$ are part-time caregivers and $5.9 \%$ had previous caregiving experience for dementia patients. No one had previous training for dementia care. (Table 3 ) 
Table (1): Socio-demographic data of dementia patients:

\begin{tabular}{|c|c|c|c|c|c|}
\hline & & Min. & Max. & Mean & SD \\
\hline \multirow[t]{2}{*}{ Age } & & 60.00 & 86.00 & 73.70 & 6.44 \\
\hline & & $\mathbf{N}$ & & $\%$ & \\
\hline \multirow[t]{2}{*}{ Sex } & Male & 29 & & $28.7 \%$ & \\
\hline & Female & 72 & & $71.3 \%$ & \\
\hline \multirow[t]{3}{*}{ Marital status } & Married & 31 & & $30.7 \%$ & \\
\hline & Widow/ Widower & 68 & & $67.3 \%$ & \\
\hline & Divorced & 2 & & $2.0 \%$ & \\
\hline \multirow[t]{4}{*}{ Education level } & Illiterate & 54 & & $53.5 \%$ & \\
\hline & Primary & 26 & & $25.7 \%$ & \\
\hline & Secondary & 12 & & $11.9 \%$ & \\
\hline & Post-secondary & 9 & & $8.9 \%$ & \\
\hline \multirow[t]{2}{*}{ Income } & Sufficient & 53 & & $52.5 \%$ & \\
\hline & Not sufficient & 48 & & $47.5 \%$ & \\
\hline Living place & Home & 101 & & $100.0 \%$ & \\
\hline \multirow{2}{*}{$\begin{array}{l}\text { Living With } \\
\text { whom }\end{array}$} & Alone & 2 & & $2.0 \%$ & \\
\hline & With caregiver & 99 & & $98.0 \%$ & \\
\hline \multirow[t]{2}{*}{ Residence } & Urban & 93 & & $92.1 \%$ & \\
\hline & Rural & 8 & & $7.9 \%$ & \\
\hline \multirow{3}{*}{$\begin{array}{l}\text { Number of those } \\
\text { who can take care } \\
\text { of patient }\end{array}$} & 1 & 58 & & $57.4 \%$ & \\
\hline & 2 & 37 & & $36.6 \%$ & \\
\hline & 3 & 6 & & $5.9 \%$ & \\
\hline
\end{tabular}

*Income classified sufficient or not according having financial problem or not.

Table (2) :Cognitive and Functional assessment of patients :

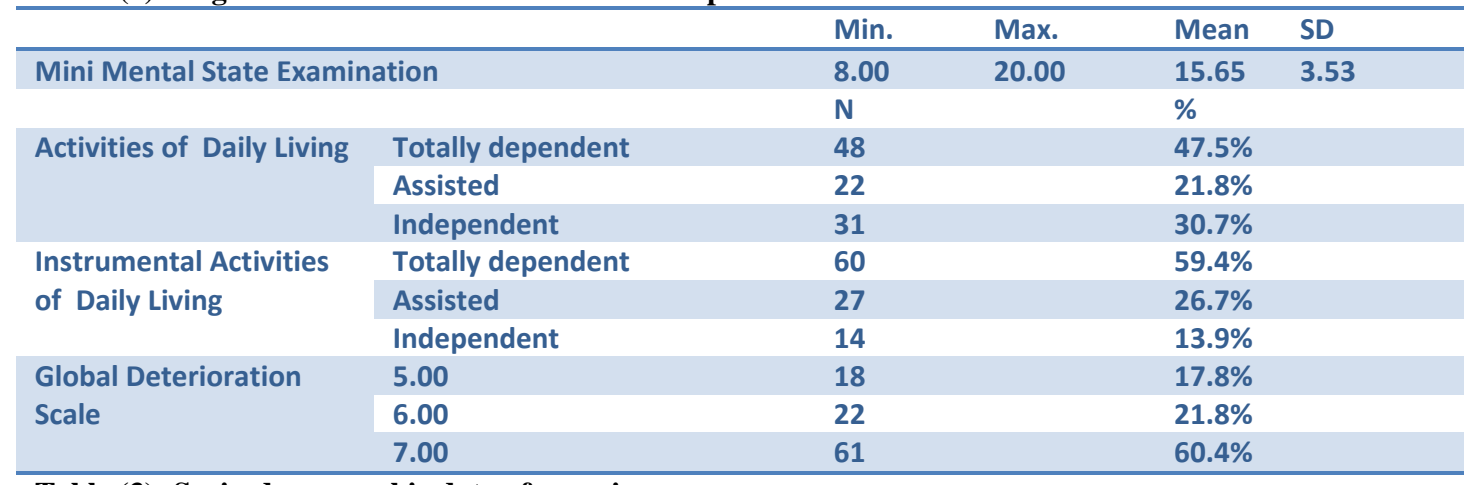

Table (3): Socio-demographic data of caregivers:

\begin{tabular}{|c|c|c|c|c|c|}
\hline & & Min. & Max. & Mean & SD \\
\hline \multirow[t]{2}{*}{ Caregiver age } & & 22.00 & 80.00 & 46.42 & 13.76 \\
\hline & & $\mathbf{N}$ & & $\%$ & \\
\hline \multirow[t]{2}{*}{ Caregiver sex } & Male & 30 & & $29.7 \%$ & \\
\hline & Female & 71 & & $70.3 \%$ & \\
\hline \multirow{4}{*}{$\begin{array}{l}\text { Caregiver } \\
\text { Education }\end{array}$} & Illiterate & 6 & & $5.9 \%$ & \\
\hline & Primary & 13 & & $12.9 \%$ & \\
\hline & Secondary & 19 & & $18.8 \%$ & \\
\hline & Post-secondary & 63 & & $62.4 \%$ & \\
\hline \multirow{3}{*}{$\begin{array}{l}\text { Relation to the } \\
\text { patient }\end{array}$} & First degree & 82 & & $81.2 \%$ & \\
\hline & Other degree & 19 & & $18.8 \%$ & \\
\hline & Not a relative & 0 & & $0 \%$ & \\
\hline \multirow{2}{*}{$\begin{array}{l}\text { Multiple } \\
\text { caregivers for a } \\
\text { patient }\end{array}$} & Yes & 53 & & $52.5 \%$ & \\
\hline & No & 48 & & $47.5 \%$ & \\
\hline \multirow[t]{2}{*}{ Care-giving time } & Part time & 54 & & $53.5 \%$ & \\
\hline & Full time & 47 & & $46.5 \%$ & \\
\hline \multirow{3}{*}{$\begin{array}{l}\text { Support type } \\
\text { offered by } \\
\text { caregivers }\end{array}$} & Physical support & 22 & & $21.8 \%$ & \\
\hline & Financial support & 21 & & $20.8 \%$ & \\
\hline & Both & 58 & & $57.4 \%$ & \\
\hline \multirow[t]{2}{*}{ Previous training } & Yes & 0 & & $0 \%$ & \\
\hline & No & 101 & & $100.0 \%$ & \\
\hline \multirow{2}{*}{$\begin{array}{l}\text { Previous care- } \\
\text { giving }\end{array}$} & Yes & 6 & & $5.9 \%$ & \\
\hline & No & 95 & & $94.1 \%$ & \\
\hline
\end{tabular}


Table (4): Burden of care-giving and types of support needed by caregivers:

\begin{tabular}{|c|c|c|c|}
\hline Care burden : & & $\mathbf{N}$ & $\%$ \\
\hline \multirow[t]{2}{*}{ Fear of future burden } & Yes & 99 & $98.0 \%$ \\
\hline & No & 2 & $2.0 \%$ \\
\hline \multirow[t]{2}{*}{ Feeling Physical burden } & Yes & 90 & $89.1 \%$ \\
\hline & No & 11 & $10.9 \%$ \\
\hline \multirow[t]{2}{*}{ Feeling Psychological burden } & Yes & 90 & $89.1 \%$ \\
\hline & No & 11 & $10.9 \%$ \\
\hline \multirow[t]{2}{*}{ Feeling Financial burden } & Yes & 70 & $69.3 \%$ \\
\hline & No & 31 & $30.7 \%$ \\
\hline \multicolumn{2}{|l|}{ Types of support needed by caregivers : } & $\mathbf{N}$ & $\%$ \\
\hline \multirow[t]{2}{*}{ Need for support } & Yes & 99 & $98.0 \%$ \\
\hline & No & 2 & $2.0 \%$ \\
\hline \multirow[t]{2}{*}{ Medical support } & Yes & 81 & $80.2 \%$ \\
\hline & No & 20 & $19.8 \%$ \\
\hline \multirow[t]{2}{*}{ Physical support } & Yes & 60 & \multirow[t]{2}{*}{$59.4 \%$} \\
\hline & No & 41 & \\
\hline \multirow[t]{2}{*}{ Psychological support } & Yes & 55 & \multirow[t]{2}{*}{$54.5 \%$} \\
\hline & No & 46 & \\
\hline \multirow[t]{2}{*}{ Financial support } & Yes & 48 & \multirow[t]{2}{*}{$47.5 \%$} \\
\hline & No & 53 & \\
\hline \multirow[t]{2}{*}{ Social support } & Yes & 9 & $8.9 \%$ \\
\hline & No & 92 & $92.1 \%$ \\
\hline
\end{tabular}

Table (5): Caregivers' knowledge regarding disease effect on patient:

\begin{tabular}{llll}
\hline $\begin{array}{l}\text { Caregivers' previous knowledge } \\
\text { about dementia and required care }\end{array}$ & No knowledge & 101 & $101 \%$ \\
\hline $\begin{array}{l}\text { Dementia patient needs special } \\
\text { care }\end{array}$ & Yes & 94 & $93.1 \%$ \\
Dementia affects safety of patient & No & 7 & $6.9 \%$ \\
& Yes & 55 & $54.5 \%$ \\
\cline { 2 - 3 } Dementia affects sleep & No & 46 & $45.5 \%$ \\
\hline \multirow{2}{*}{ Dementia affects nutrition } & Yes & 75 & $74.3 \%$ \\
Dementia affects behavior & Yes & 26 & $25.7 \%$ \\
& No & 49 & $48.5 \%$ \\
Dementia affects activity & Yes & 52 & $51.5 \%$ \\
& No & 89 & $88.1 \%$ \\
\hline
\end{tabular}

Caregivers were asked about the burden they face during dementia care and showed that the commonest reported burden was fear of future burden $(98 \%)$, then feeling physical burden $(89.1 \%)$, psychological burden $(89.1 \%)$ and the least common was the financial burden $(69.3 \%)$. (Table 3$)$

Regarding the needed support to decrease this burden, the commonest reported needed supports was medical support $(80.2 \%)$, followed by physical support (59.4\%), psychological support (54.5\%), financial support $(47.5 \%)$ and the least needed was social support $(8.9 \%)$. (Table 4$)$
From caregivers' perspectives, $93.1 \%$ know that dementia patieFts may need special care, $88.1 \%$ know that dementia affects behavior, $74.3 \%$ of caregivers know that dementia affects sleep, 54.5\% know that dementia affects patient's safety, 53.5\% know that dementia affects activity, and $48.5 \%$ know that dementia affects nutrition. No one of the caregivers had previous knowledge about dementia or required care. (Table 5) 


\section{Discussion:}

Dementia is an incurable disorder for which traditional health outcome measures (e.g., disease remission, prolonged survival) are often unachievable or hold little meaning. Although a variety of measures have been developed that assess control of behavioral symptoms and caregiver outcomes, these may not capture everything that may be important to patients and their caregivers as they face the behavioral, medical and social consequences of dementia. (Jennings, et al., 2017)

Increasing numbers of cases will pose undue burden on individuals who have dementia, their caregivers, and healthcare systems more generally. So surveys should be done to estimate this burden, help to relieve it and improve patients' quality of life. (Nichols et al., 2019)

In this study, $98 \%$ of our studied population had fear of future burden. This agrees with the results of a study done by Givens et al., (2012) which reported that the uncertainty about the future may create an ambiguous situation for family members and increase the burden on the caregiver.

Burden has several forms either physical or psychological or financial. Regarding our population, the most prevalent burden was the physical one $(89.1 \%)$ and $98 \%$ caregivers reported their need for physical support. In Krutter et al., (2020) they reported a similar burden as $98 \%$ of the caregivers of dementia patients and home-care nurses complained of physical burden. One of the most common causes of burden reported by Liu et al., (2017) is that the lower functional status of the patient which was associated with higher caregiver burden, lower life satisfaction, and higher degrees of depression and anxiety.

Regarding psychological burden among our studied population, it affects $89.1 \%$ of them and $54.5 \%$ reported the need for psychological support.

In agreement with our results Krutter et al., (2020) reported that $99 \%$ of caregivers for dementia patients had a psychological burden. As behavioral problems associating dementia may increase psychological burden, it was found that emotional support for caregivers who have difficulty in coping with behavioral problems may enhance therapeutic engagement and their readiness to use behavior management strategies. (Gitlin \& Rose 2014).

Psycho-educational approaches are most effective at improving caregiver knowledge, reducing caregiver burden and depression symptoms, and increasing subjective well-being and caregiver satisfaction. (Sörensen et al., 2006)

The least reported burden among the studied population was the financial one. The prevalence of financial burden was $69.3 \%$ and $47.5 \%$ of dementia caregivers needed financial support. That's because dementia has huge economic impact on people living with the illness, their Caregivers, and society as a whole. Better support for people with dementia and their caregivers, as well as fair and efficient financing of social care services, are essential to address the current and future challenges of dementia. (Wittenberg et al., 2019)

The current study revealed that $98 \%$ of the studied population feel the need for some sort of support. In the same way, Maki et al., (2018) agreed that support for dementia patients should be provided with medical social workers who are responsible for coordinating community care by linking people with dementia and their caregivers with community sources. Caregivers are considered as team members to provide support in daily living.

Medical support was important for $80.2 \%$ of the studied population. Therefore, Hum et al., (2014) made attention to family physicians who can coordinate care across health sectors, community services, and health professionals and consider solutions to individuals' and caregivers' problems across the stages and transitions of dementia, including advance care planning.

Dementia caregivers are at an increased risk of various health problems including higher levels of chronic conditions such as diabetes, arthritis, ulcers, anemia, cardiovascular problems, lower immunity, and poorer self-rated health. They need more doctor visits and use of prescription medications and showed decreased engagement in preventative health behaviors such as exercise. They also have greater likelihood of drinking alcohol, smoking, and poor sleep patterns. (Schulz \&Martire, 2004). So medical support for both patients and their caregivers is of great paramount.

No one of the studied population had previous information about dementia progression or had previous discussion about goals of care for dementia patients. In the same way, Glynn et al., (2017) study in Ireland about public knowledge and understanding of dementia showed a poor level of information among the studied population.

But in the Australian population, a survey done investigating knowledge about dementia, its risk 
factors and burden showed that $82 \%$ of the studied population had good knowledge. That is due to the role of media in focusing on dementia symptoms and burden. (Low \& Anstey, 2009)

Wang et al., (2018) proved that the limited availability of dementia-specific continuing education programs is an important contributing factor to the lower level of knowledge about dementia among caregivers.

Raising public knowledge of dementia is crucial for optimizing care, enhancing the quality of life of dementia patients, and decreasing the caregiving burden. Increasing knowledge levels will help to tackle the stigma of dementia and open up a better informed-debate about the needs of these patients. (Rimmer et al., 2005)

This study revealed that $93.1 \%$ of caregivers agreed that dementia patients may need special care. Prevalence of caregivers who knew that dementia may affect patients' behavior, sleep, safety, activity and nutrition was $88.1 \%, 74.3 \%, 54.5 \%, 53.5 \%$ and $48.5 \%$ respectively. Most of their knowledge emerged during caregiving process either than previous education.

In the same way, Caregivers proved that various symptoms of dementia may affect the quality of life of the elderly with dementia. Pereira \& Soares, (2015) showed that neuropsychiatric symptoms, depression, and poor sleep quality in elderly people with dementia lead to loss of autonomy and independence.

Knowledge of dementia is evinced to be a protective factor against caregivers' subjective distress. This reinforces the need for caregivers to improve their understanding towards dementia even if they have been a caregiver for a prolonged period of time. (Sörensen \& Conwell, 2011)

\section{Conclusions}

This study shows that caregivers of dementia patients face high rates of psychological, physical, and financial burden. They are in need of more support. Knowledge about dementia is poor among the studied population. So, further studies are needed to investigate the causes of poor knowledge and the ideal ways to deliver health education that should be applied to all caregivers.

\section{References:}

1- Edition F. Diagnostic and statistical manual of mental disorders (2013). Am Psychiatric Assoc.;21.

2- Elshahidi MH, Elhadidi MA, Sharaqi AA, Mostafa A, Elzhery MA (2017): Prevalence of dementia in Egypt: a systematic review.
Neuropsychiatric Disease and Treatment. ;13:715.

3- Alzheimer's Association (2018): 2018 Alzheimer's disease facts and figures. Alzheimer's \& Dementia.1;14(3):367-429.

4- Case SM, O'Leary J, Kim N, Tinetti ME, Fried TR (2015): Older adults' recognition of trade-offs in healthcare decision-making. Journal of the American Geriatrics Society ;63(8):1658-62.

5- Alzheimer's Association (2012): 2012 Alzheimer's disease facts and figures. Alzheimer's \& Dementia.1;8(2):131-68.

6- Wang XR, Robinson KM, Carter-Harris $L$ (2014): Prevalence of chronic illnesses and characteristics of chronically ill informal caregivers of persons with dementia. Age and Ageing. 1;43(1):13741.

7- Alzheimer's Association (2016): 2016 Alzheimer's disease facts and figures. Alzheimer's \& Dementia. 1;12(4):459-509.

8- Freedman VA, Spillman BC (2014): Disability and care needs among older Americans. The Milbank Quarterly ;92(3):509-41.

9- Grigorovich A, Rittenberg N, Dick T, McCann A, Abbott A, Kmielauskas A, Estioko V, Kulasingham S, Cameron JI (2016): Roles and coping strategies of sons caring for a parent with dementia. American Journal of Occupational Therapy. 1;70(1):7001260020p1-9.

10- Reisberg B, Ferris SH, de Leon MJ, Crook T(1982): The Global Deterioration Scale for assessment of primary degenerative dementia. The American journal of psychiatry.

11- Folstein MF, Folstein SE, McHugh PR (1975): "Mini-mental state": a practical method for grading the cognitive state of patients for the clinician. Journal of psychiatric research. 1;12(3):189-98.

12- Katz S, Ford AB, Moskowitz RW, Jackson BA, Jaffe MW. Studies of illness in the aged: the index of ADL (1963): a standardized measure of biological and psychosocial function. jama; 185(12):914-9

13- Lawton MP, Brody EM (1969): Assessment of older people: self-maintaining and instrumental activities of daily living. The gerontologist.

14- Jennings LA, Palimaru A, Corona MG, Cagigas XE, Ramirez KD, Zhao T, Hays RD, Wenger NS, Reuben DB (2017): Patient and caregiver goals for dementia care. Quality of Life Research. 1;26(3):685-93.

15- Nichols E, Szoeke CE, Vollset SE, Abbasi N, Abd-Allah F, Abdela J, Aichour MT, Akinyemi RO, Alahdab F, Asgedom SW, Awasthi A (2019): Global, regional, and national burden of Alzheimer's disease and other dementias, 1990-2016: a systematic analysis for the Global Burden of Disease Study 2016. The Lancet Neurology.1;18(1):88-106.

16- Givens JL, Lopez RP, Mazor KM, Mitchell SL (2012): Sources of stress for family members of nursing home residents with advanced dementia. Alzheimer disease and associated disorders ;26(3):254.

17-Krutter S, Schaffler-Schaden D, Essl-Maurer R, Wurm L, Seymer A, Kriechmayr C, Mann E, Osterbrink J, Flamm M (2020): Comparing perspectives of family caregivers and healthcare professionals regarding caregiver burden in dementia care: results of a mixed methods study in a rural setting. Age and ageing 27;49(2):199-207.

18- Liu S, Li C, Shi Z, Wang X, Zhou Y, Liu S, Liu J, Yu T, Ji Y (2017): Caregiver burden and prevalence of depression, anxiety and sleep disturbances in A Izheimer's disease caregivers in China. Journal of clinical nursing ;26(9-10):1291-300.

19- Gitlin LN, Rose K (2014): Factors associated with caregiver readiness to use nonpharmacologic strategies to manage dementia-related behavioral symptoms. International journal of geriatric psychiatry ;29(1):93-102.

20- Sörensen S, Duberstein P, Gill D, Pinquart M (2006): Dementia care: mental health effects, intervention strategies, and clinical implications. The Lancet Neurology.1;5(11):961-73.

21- Wittenberg R, Knapp M, Hu B, Comas-Herrera A, King D, Rehill A, Shi C, Banerjee S, Patel A, Jagger C, Kingston A (2019): The costs of dementia in England. International Journal of Geriatric Psychiatry;34(7):1095-103. 
22- Maki Y, Sakurai T, Okochi J, Yamaguchi H, Toba K (2018): Rehabilitation to live better with dementia. Geriatrics \& gerontology international ;18(11):1529-36.

23- Hum S, Cohen C, Persaud M, Lee J, Drummond N, Dalziel W, Pimlott N (2014): Role expectations in dementia care among family physicians and specialists. Canadian Geriatrics Journal ;17(3):95.

24- Schulz R, Martire LM (2004): Family caregiving of persons with dementia: prevalence, health effects, and support strategies. The American journal of geriatric psychiatry. 1;12(3):240-9.

25- Glynn RW, Shelley E, Lawlor BA (2017): Public knowledge and understanding of dementia-evidence from a national survey in Ireland. Age and ageing. 1;46(5):865-9.

26- Low LF, Anstey KJ (2009): Dementia literacy: recognition and beliefs on dementia of the Australian public. Alzheimer's \& Dementia. 1;5(1):43-9.

27- Wang Y, Xiao LD, Luo Y, Xiao SY, Whitehead C, Davies 0. (2018): Community health professionals' dementia knowledge, attitudes and care approach: a cross-sectional survey in Changsha, China. BMC geriatrics; 18(1):1-0.

28- Rimmer E, Wojciechowska M, Stave C, Sganga A, O'Connell B (2005): Implications of the Facing Dementia Survey for the general population, patients and caregivers across Europe. International Journal of Clinical Practice; 59:17-24.

29- Pereira LS, Soares SM (2015): Factors influencing the quality of life of family caregivers of the elderly with dementia. Ciencia \& saude coletiva. 1;20(12).

30- Sörensen S, Conwell Y (2011): Issues in dementia caregiving: effects on mental and physical health, intervention strategies, and research needs. The American Journal of Geriatric Psychiatry. $1 ; 19(6): 491-6$. 